\title{
Study on Droplet Dispersion Influenced by Ventilation and Source Configuration in Classroom Settings Using Low-cost Sensor Network
}

Special Issue:

Special Issue on Air Quality in a Changed World: Regional, Ambient, and Indoor Air Concentrations from the COVID to Post-COVID Era (I)

\section{OPEN ACCESS}

Received: September 3, 2021 Revised: October 25, 2021 Accepted: October 25, 2021

\section{${ }^{*}$ Corresponding Author:} qou@umn.edu

\section{Publisher:}

Taiwan Association for Aerosol Research

ISSN: $1680-8584$ print

ISSN: 2071-1409 online

(c) Copyright: The Author(s). This is an open access article distributed under the terms of the Creative Commons Attribution License (CC BY 4.0), which permits unrestricted use, distribution, and reproduction in any medium, provided the original author and source are cited.

\author{
Weiqi Chen, Dong-Bin Kwak, Jonathon Anderson, Kaushik Kanna, \\ Chenxing Pei, Qingfeng Cao, Qisheng Ou*, Seong Chan Kim, Thomas H. Kuehn, \\ David Y.H. Pui
}

Particle Technology Laboratory, Mechanical Engineering, University of Minnesota, Minneapolis 55455, USA

\section{ABSTRACT}

The COVID-19 virus can transmit through airborne expiratory droplets and thus, the viral transmission can take place between the occupants in the isolated room. With the school reopening under the current COVID-19 pandemic, it is urgent to improve the classroom ventilation system to mitigate the risk of virus transmission. The present study developed a particle concentration monitoring network (PCMN) using low-cost sensors and deployed it to explore the dispersion of the droplet particles under different ventilation settings and aerosol configurations. Our experiment shows the advance of using a low-cost sensor network on spatiotemporal air monitoring and demonstrates indoor particle concentration level and distribution are strongly impacted by the ventilation setting and source location. Two recommendations on reducing the viral risk in the classroom were derived from the study. The first is the respiratory droplet source, e.g., the instructor, should be in the location such that the particle dispersion opposes the ventilation flow. The second is the air handling unit (AHU) and fan coil unit (FCU) should be both turned on during class hours despite whether there is a need for thermal comfort, as it allows higher and more uniform ventilation flow to resolve the issue of the dead air zone.

Keywords: COVID-19, Classroom ventilation, Low-cost sensor, $\mathrm{PM}_{2.5}$, Indoor air monitoring

\section{INTRODUCTION}

It is known that the COVID-19 virus can be carried by the airborne expiratory droplets from an infected individual (Asadi et al., 2020; Buonanno et al., 2020; Feng et al., 2020; Leung et al., 2020; Morawska and Cao, 2020) and transmit infection via airflows generated by room ventilation, air conditioners, or wind (Kwon et al., 2020; Moses et al., 2020). Recent research by Shao et al. demonstrated computational modeling results of COVID-19 airborne transmission under several practical settings such as elevators, classrooms, and supermarkets (Shao et al., 2021), and Hobday and Cason emphasized the importance of air ventilation to mitigate the risk of viral transmissions in isolated rooms (Hobday and Cason, 2009). However, only a few experimental studies have been conducted on respiratory droplet dispersion which is critical in validating numerical simulations and designing optimum ventilation systems to mitigate virus transmission between indoor occupants, since current heating, ventilation, and air conditioning (HVAC) settings are designed for thermal comfort, filtration of outdoor contaminant, and energy saving, but not for minimizing the viral dispersion inside the room. Moreover, this type of study requires spatiotemporal air monitoring, which can be the paradigm of the low-cost sensor technology raised in recent years (Jayaratne et al., 2020; Owoade et al., 2021; Rai et al., 2017). Many low-cost sensors studies dedicated the effort to indoor monitoring (Chojer et al., 2020). However, only a few of them emphasized the high-resolution spatial distribution/dispersion of airborne particles. 
This study has two goals, the first is to develop a low-cost wireless particle concentration monitoring network (PCMN) and demonstrate its advantage in high-resolution indoor particle spatial distribution monitoring. The second is to study the respiratory droplet dispersion under different ventilation settings and source locations in a typical University classroom to derive recommendations on minimizing indoor viral risk. Nine custom-built particle concentration monitors (PCMs) were developed to form a PCMN to monitor the particle concentration spatial and temporal distribution. Test particles were generated to mimic the respiratory droplets from the instructor to the audience. The results show that the spatial particle distribution is strongly affected by the ventilation conditions and source configuration even in a relatively small classroom (capacity around 30 occupants), which can be important for viral risk assessment.

\section{METHODS}

\subsection{Setup}

As shown in Figs. 1(a) and 1(c), the spatial airborne particle concentrations were monitored at nine locations in a typical classroom (length $10.2 \times$ width $6.8 \times$ height $2.7 \mathrm{~m}^{3}$ ) at the University of Minnesota to study the respiratory droplet dispersion under different air ventilation conditions. Nine battery-operated PCMs were designed and built to measure airborne particle mass concentration changes in real-time. Each PCM was placed in the center of the student desk with a height of $0.73 \mathrm{~m}$. The desks are aligned in 5 rows and 3 columns (Fig. $1(\mathrm{c})$ ). $1 \% \mathrm{NaCl}$ solution
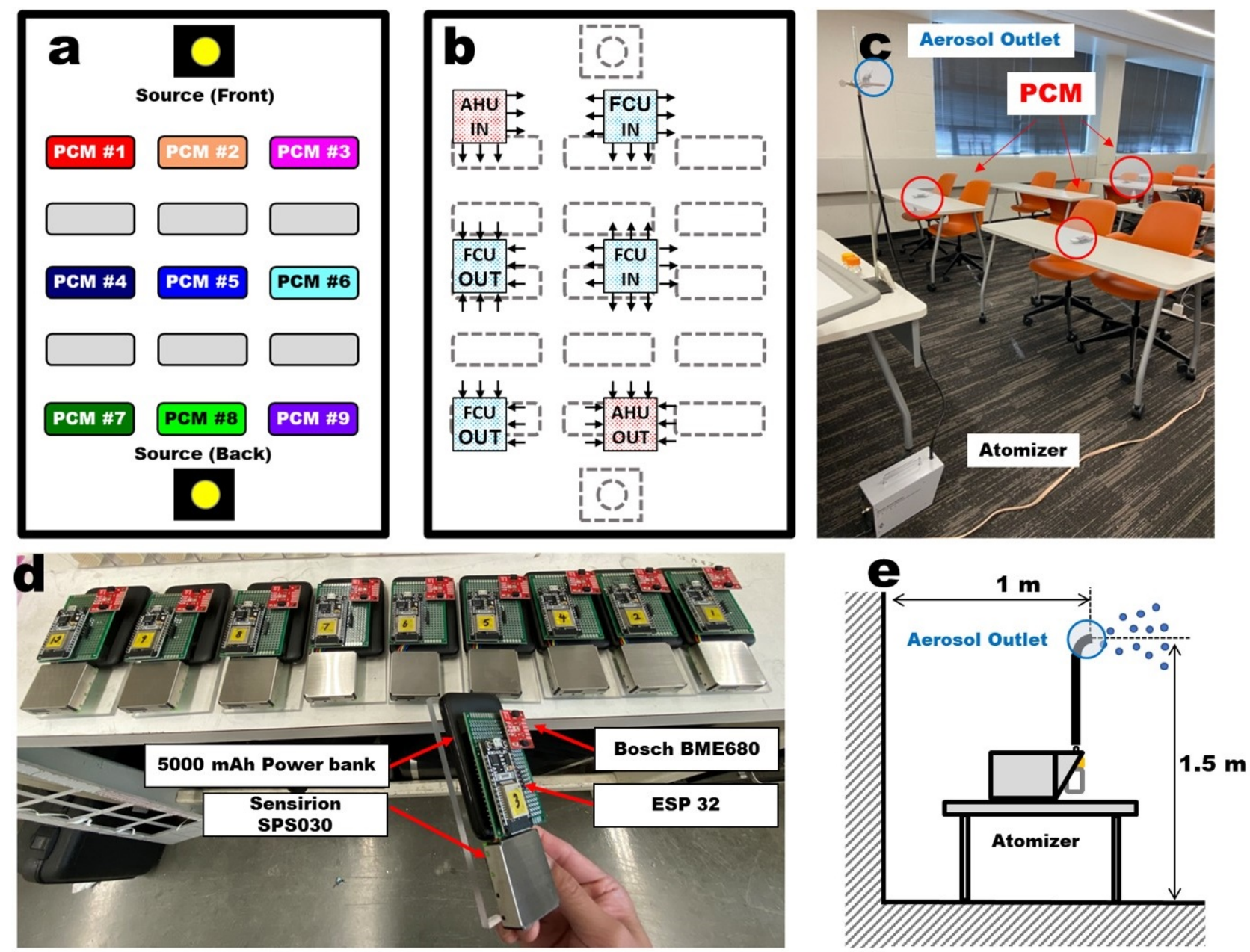

Fig. 1. Setup and devices: (a) Configuration of the particle concentration monitoring network (PCMN) that consists of nine particle concentration monitors (PCMs); (b) Ductwork arrangement for the air handling unit (AHU) and fan coil unit (FCU); (c) Photo of the setup; (d) The PCMs developed in this study; (e) Configuration of aerosol generation. 
was used to generate test particles to mimic the respiratory droplets from the instructor using a portable atomizer (3079A, TSI). The aerosol outlet was positioned at $1 \mathrm{~m}$ away from the center of the front or back wall, and $1.5 \mathrm{~m}$ above the floor as shown in Fig. 1(e). The atomizer nozzle velocity was $5 \mathrm{~m} \mathrm{~s}^{-1}$ to simulate a loud speaking condition (Traunmüller and Eriksson, 2000) and had a number-based mean size of around $0.3 \mu \mathrm{m}$ which represents airborne coughing droplet size (Nicas et al., 2005; Papineni and Rosenthal, 1997; Zayas et al., 2012). Note that the initial cough droplet size may be larger and in the micron size range (Yang and Marr, 2011). Considering large droplets can quickly settle to the ground and are not ideal for a dispersion study, while the smaller droplets stay in the air for a much longer time and are thus more favorable for viral transmission and of more concern. So, the $0.3 \mu \mathrm{m}$ test droplet size is chosen because it is small enough for a particle dispersion study, but also within the cough droplets size range.

\subsection{Classroom Ventilation System}

There are two types of ventilation systems in a typical University classroom, air handling unit (AHU) and fan coil unit (FCU). The AHU operates continuously to provide fresh outdoor air and removes outside airborne particles with Minimum efficiency reporting value (MERV) 8 prefilters and MERV 15 final filters with a flow rate of 100-300 CFM (0.9-2.7 ACH, Air changes per hour). The FCU typically runs only during the summertime to provide cooling in a recirculation mode and has a MERV 13 air filter with a flow rate of 750 CFM (6.8 ACH). The test classroom layout including the locations of the PCM and AHU/FCU perforated grill on the ceiling are illustrated in Fig. 1(b).

\subsection{Particle Concentration Monitoring Network (PCMN)}

The PCMN consists of multiple PCMs developed in this study. The PCM is an open-source, standalone hardware and software sensor monitoring platform for measuring the residual particles in the room (Fig. 1(d)). The monitoring platform is designed to measure the particulate matter (PM) mass and number concentration, pressure, temperature, and relative humidity. The hardware of the PCM consists of (1) a PM sensor (SPS30, Sensirion), (2) an environmental sensor (BME680, Bosch) (3) a microcontroller (ESP32, Espressif) to acquire data from each sensor, and (4) a 5000 mAh power bank. The SPS30 PM sensor is an optical sensor utilizing a laser light scattering technique to measure $\mathrm{PM}_{1.0}, \mathrm{PM}_{2.5}, \mathrm{PM}_{4}$, and $\mathrm{PM}_{10}$ for particle mass concentration and $\mathrm{PM}_{0.5}, \mathrm{PM}_{1.0}, \mathrm{PM}_{2.5}, \mathrm{PM}_{4}$, and $\mathrm{PM}_{10}$ for particle number concentration. The SPS30 sensor can sample the ambient air by an internal fan, which makes the sensing real-time and reliable. It is capable of measuring particle mass concentration from 1 to $1000 \mu \mathrm{g} \mathrm{m}^{-3}$ with $\pm 10 \%$ error. BME680 is a low-power gas sensor that can measure ambient air pressure, temperature \& humidity from $300 \mathrm{hPa}$ to $1100 \mathrm{hPa}$ pressure, $-25^{\circ} \mathrm{C}$ to $85^{\circ} \mathrm{C}$ temperature, and $0 \%$ to $100 \%$ relative humidity. It's also capable of detecting the breath-VOC (b-VOC) mixture such as ethane, isoprene /2-methyl-1,3-butadiene, ethanol. Acetone, carbon monoxide. PCM makes use of ESP32 a relatively new microcontroller that contains a dualcore CPU, $512 \mathrm{kB}$ static random-access memory (SRAM), and 4-8MB external memory. The high processing power and large memory support make it suitable for heavy tasks such as streaming data from the internet (Internet-of-Things sensor). Most importantly, the ESP32 has built-in WiFi and Bluetooth, so no additional radio modules are needed. The sensor monitoring platform consumes $\sim 15 \mathrm{~mA}$ when the system is sleeping and $\sim 110 \mathrm{~mA}$ when it is active. With a 1-minute sampling interval setting (sleep for 50 seconds and active for 10 seconds) and the $5000 \mathrm{mAh}$ power bank, the device can monitor the ambient air and airborne particles continuously for up to $\sim 162$ hours. The cost of a PCM is less than 80 US dollars and depends on the purchased quantity of the components.

The sensor data was uploaded and collected wirelessly on a cloud server system for a userfriendly data acquisition. For the software of the PCMN, we developed a custom-built website running on a University server to exchange messages using Mosquitto, which is an open-source message broker that implements Message Queuing Telemetry Transport (MQTT) protocol. A node.js server was used to process all MQTT messages from the devices and store them in an SQLite database. Chart.js is used for data visualization. This custom-built web platform is protected by password and allow users to add/edit/remove devices and sensor values and send event comments to the sensors and specify the sensor sampling time. The website also allows online real-time data plotting and automatic data cloud backup. 


\subsection{Experiment Procedure}

Two types of experiments were conducted in this study: a sensor validation experiment to calibrate the PCMs and particle dispersion experiments under different ventilation conditions and source configuration to study how to minimize the viral risk in the room during class hours. For sensor calibration test, one DustTrak (DRX 8533, TSI), one scanning mobility particle sizer (SMPS) platform that includes a differential mobility analyzer (DMA) (3081, TSI) and a condensation particle counter (CPC) $(3756, \mathrm{TSI})$, and five PCMs were placed next to each other in the center of the room under room ambient condition with the sampling inlet at the same height to avoid vertical concentration variation. $\mathrm{NaCl}$ aerosol was first atomized to fill up the classroom while AHU and FCU were off, and with two mixing fans at the front and backside of the room to promote uniform mixing. When room aerosol reached desired concentration, the particle generation was stopped, and both AHU (100 CFM) and FCU (750 CFM) were turned on to allow particle decay.

For particle dispersion experiments, the nine PCMs were set up as shown in Fig. 1(a) to measure the particle concentration change over time in each location. The experiments started with 30 minutes of test particles generation. After that, the particle atomization was stopped to allow the concentration to decay for another 30 minutes. Both AHU (300 CFM) and FCU (750 CFM) were on during the entire experiments (FCU may be off depending on the test conditions).

\section{RESULTS AND DISCUSSION}

\subsection{Sensor Calibration}

Fig. 2(a) validates the PCM accuracy by comparing it to the research-grade instruments (DustTrak and SMPS). The DustTrak was calibrated using the $\mathrm{NaCl}$ test aerosol using gravimetric analysis with the built-in filter cassette. The bias between DustTrak and SMPS at the early measurement was due to the lower measurable size range of SMPS. The large droplets have a heavy contribution in mass and thus lead to lower measured mass concentration from SMPS even with a small number count. The DustTrak and SMPS reading soon converged because the large droplets quickly settle to the ground and/or evaporate into smaller droplets that can be detected by SMPS. Overall, a good agreement between DustTrak and SMPS is shown, which indicates the reliability of the reference data. Raw measurements of PCM have a similar trend but small difference in values compared to the reference data, which is of expectation, since particle characteristics, concentration, relative humidity, and temperature can all impact the sensor reading because of its light scattering principle (Rai et al., 2017; Wang et al., 2015). Fig. 2(b) compares the raw averaged PCM measurement to the DustTrak results. The linear regression with $R^{2}$ of 0.99 indicates the high linearity. The fitting was used to calibrate the raw PCM measurements. The calibrated PCM is as accurate as of the research-grade instruments as shown in Fig. 2(a). Moreover, the readings
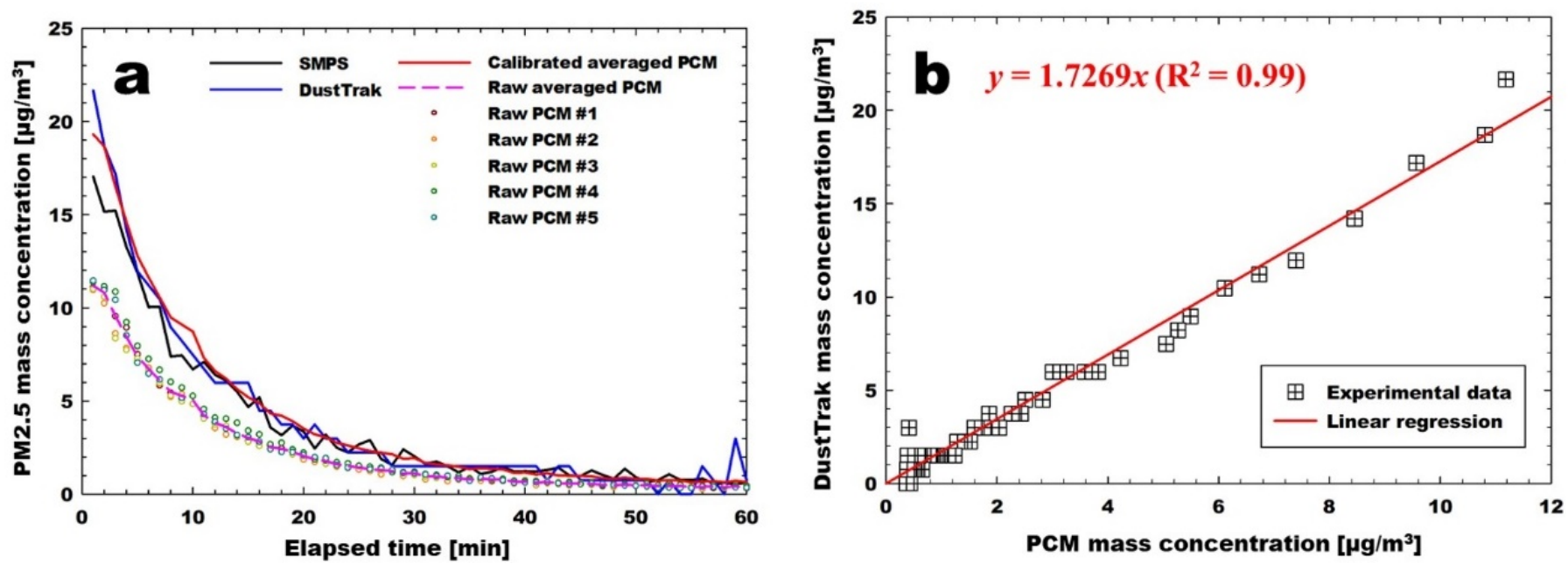

Fig. 2. (a) Comparison of $\mathrm{PM}_{2.5}$ mass concertation between particle concentration monitors (PCMs), scanning mobility particle sizer (SMPS), and DustTrak; (b) Sensor calibration using DustTrak. 
of the five PCMs have good agreement with each other when they were placed together. The intra-model variability can be defined using the normalized Root Mean Square Error (nRMSE) (Manikonda et al., 2016). The PCM \#2-5 have the nRMSE of 0.105, 0.111, 0.263, and 0.149, respectively, compared to PCM \#1, and thus, good intra-model consistency of the PCM sensors is demonstrated.

\subsection{Droplet Particle Dispersion Experiment}

Fig. 3 illustrates the calibrated PCM results of the droplet particle dispersion experiment under different ventilation conditions and source configurations. For every case, the concentrations of the first 10 minutes are the background ambient concentrations $\left(1-2 \mu \mathrm{g} \mathrm{m}^{-3}\right)$ before the droplet particle generation. In case A (Fig. 3(a)) (Source at front, AHU on and FCU off), there were dramatic increases in concentration at PCM locations \#2, 3, and 6 during the particle generation, about two times the concentration in other locations. This was because of the dead air zone
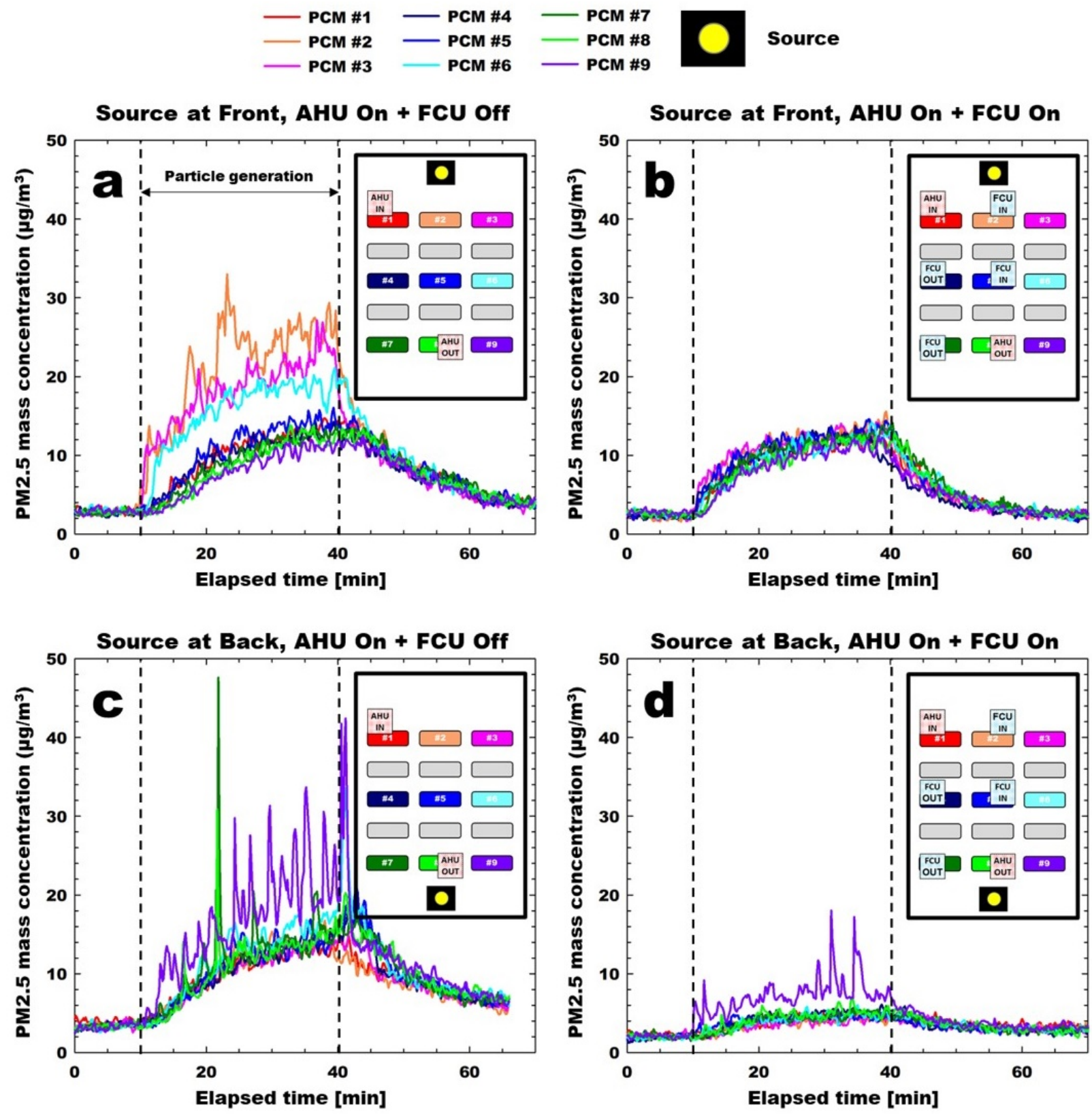

Fig. 3. Spatial particle droplet monitoring under different settings of air handling unit (AHU) and fan coil unit (FCU) and different source configurations (front or back) using the low-cost sensor network consists of nine particle concentration monitors (PCMs). 
caused by the air ventilation flow between the AHU-In and the AHU-Out. Locations closer to the source had a slightly higher concentration, but the difference due to distance was not comparable to the difference caused by the ventilation flow and duct arrangement. These highlights the importance of monitoring particle spatial distribution, and the advantage of the use of PCMN over the research-grade particle instruments. The affordable price makes it feasible to establish a sensor network to detect high particle concentration zone.

In case B (Fig. 3(b)), the FCU was turned on in addition to AHU. Results show the hot zones no longer existed. The concentrations in all locations were now similar to each other, indicating much-improved particle uniformity in the room. This was likely the result of three consequences: the FCU inlet next to the source helped disperse the particles; The diagonal intersection of FCU and AHU flow promoted better flow mixing; The higher total flow rate in the room was much higher $(300+750 \mathrm{CFM})$. Moreover, the concentration at locations $\# 1,4,5,7,8$, and 9 remains similar to case $A$. These suggest that stronger and more uniform ventilation flow in the room helps to effectively remove dead air zone to reduce the virus for some students while not increasing the risks for the others.

In case C (Fig. 3(c)), the ventilation setting was similar to case A, but the source was in the backside of the classroom, so the particle dispersed in the opposite direction of the ventilation flow. Compare to case A, the hot zone was reduced to only location \#9. This was because the opposing ventilation flow was restricting the particle dispersion with the lower flow on the right side where \#9 was at since the AHU inlet was on the left side. However, the averaged concentration of the non-hot zones was similar to those of cases A and B, likely because the ventilation flow was not high enough to oppose the particle dispersion with only the AHU on.

In case D (Fig. 3(d)), every condition was the same as case C except the FCU was turned on. Interestingly, particle concentration at all locations was significantly reduced compared to the other three conditions. Location \#9 still exhibited relatively high concentration and fluctuation due to the weaker flow on the right side of the room, but its average concentration was significantly lower compared to case $\mathrm{C}$ because of the stronger opposing ventilation flow. The comparison with case $\mathrm{C}$ demonstrates increasing flow rate can significantly reduce the concentration when the particle flow is in opposite direction, and the comparison with case B shows that the source location can strongly impact the room concentration condition.

\section{CONCLUSIONS}

A particle concentration monitoring network (PCMN) has been developed using off-the-shelf low-cost light scatter particle sensors. The risk of virus dispersion under different ventilation conditions and source configuration in a typical University classroom was studied by using PCMN to monitor the spatial particle concentration change over time. The results show that the ventilation conditions and source locations have significant impacts on the droplet particle dispersion in the room. Two recommendations are derived from this study for reducing the indoor viral risk: 1) the respiratory particle source (either instructor or students) should be at the location where the ventilation flow is in the opposite direction to droplet spread direction, so the ventilation flow can bring in restriction on the particle dispersion. Stronger ventilation flow can significantly improve the effectiveness of the above-mentioned particle restriction; 2 ) the AHU and FCU should be both turned on during class hours to allow higher and more uniform ventilation flow in the room to resolve the issue of dead air zone, whereas the concentration of airborne particles can be as high as two times of average concentration of other locations. Since the particle dispersion is strongly impacted by the ventilation flow and source, the indoor particle dispersion and the dead air zone with high particle concentration are hard to predict. Therefore, the importance of monitoring particle spatial distribution is emphasized. The use of research-grade instruments in such applications is not feasible owing to the cost. On the other hand, the use of a low-cost sensor network, i.e., $\mathrm{PCMN}$, is demonstrated to be cost-effective in particle spatial monitoring in this study.

\section{ACKNOWLEDGMENTS}

The authors thank the support of members of the Center for Filtration Research: 3M Corporation, 
Applied Materials, Inc., BASF Corporation, Boeing Company, China Yancheng Environmental Protection Science and Technology City, Cummins Filtration Inc., Donaldson Company, Inc., Entegris, Inc., Ford Motor Company, Guangxi Wat Yuan Filtration System Co., Ltd, LG Electronics Inc., MSP Corporation, Parker Hannifin, Samsung Electronics Co., Ltd., Xinxiang Shengda Filtration Technology Co., Ltd., Shigematsu Works Co., Ltd., TSI Inc., W. L. Gore \& Associates, Inc., and the affiliate member National Institute for Occupational Safety and Health (NIOSH). URL: http://www.me.umn.edu/cfr/.

\section{REFERENCES}

Asadi, S., Bouvier, N., Wexler, A.S., Ristenpart, W.D. (2020). The coronavirus pandemic and aerosols: Does COVID-19 transmit via expiratory particles? Aerosol Sci. Technol. 54, 635-638. https://doi.org/10.1080/02786826.2020.1749229

Buonanno, G., Stabile, L., Morawska, L. (2020). Estimation of airborne viral emission: Quanta emission rate of SARS-CoV-2 for infection risk assessment. Environ. Int. 141, 105794. https://doi.org/10.1016/j.envint.2020.105794

Chojer, H., Branco, P.T.B.S., Martins, F.G., Alvim-Ferraz, M.C.M., Sousa, S.I.V. (2020). Development of low-cost indoor air quality monitoring devices: Recent advancements. Sci. Total Environ. 727, 138385. https://doi.org/10.1016/j.scitotenv.2020.138385

Feng, Y., Marchal, T., Sperry, T., Yi, H. (2020). Influence of wind and relative humidity on the social distancing effectiveness to prevent COVID-19 airborne transmission: A numerical study. J. Aerosol Sci. 147, 105585. https://doi.org/10.1016/j.jaerosci.2020.105585

Hobday, R.A., Cason, J.W. (2009). The open-air treatment of pandemic influenza. Am. J. Public Health 99, 236-242. https://doi.org/10.2105/AJPH.2008.134627

Jayaratne, R., Kuhn, T., Christensen, B., Liu, X., Zing, I., Lamont, R., Dunbabin, M., Maddox, J., Fisher, G., Morawska, L. (2020). Using a network of low-cost particle sensors to assess the impact of ship emissions on a residential community. Aerosol Air Qual. Res. 20, 2754-2764. https://doi.org/10.4209/aaqr.2020.06.0280

Kwon, K.S., Park, J.I., Park, Y.J., Jung, D.M., Ryu, K.W., Lee, J.H. (2020). Evidence of long-distance droplet transmission of SARS-CoV-2 by direct air flow in a restaurant in Korea. J. Korean Med. Sci. 35, 1-8. https://doi.org/10.3346/jkms.2020.35.e415

Leung, N.H.L., Chu, D.K.W., Shiu, E.Y.C., Chan, K.H., McDevitt, J.J., Hau, B.J.P., Yen, H.L., Li, Y., Ip, D.K.M., Peiris, J.S.M., Seto, W.H., Leung, G.M., Milton, D.K., Cowling, B.J. (2020). Respiratory virus shedding in exhaled breath and efficacy of face masks. Nat. Med. 26, 676-680. https://doi.org/10.1038/s41591-020-0843-2

Manikonda, A., Zíková, N., Hopke, P.K., Ferro, A.R. (2016). Laboratory assessment of low-cost PM monitors. J. Aerosol Sci. 102, 29-40. https://doi.org/10.1016/j.jaerosci.2016.08.010

Morawska, L., Cao, J. (2020). Airborne transmission of SARS-CoV-2: The world should face the reality. Environ. Int. 139, 105730. https://doi.org/10.1016/j.envint.2020.105730

Moses, F.W., Gonzalez-Rothi, R., Schmidt, G. (2020). COVID-19 Outbreak associated with air conditioning in restaurant, Guangzhou, China, 2020. Emerg. Infect. Dis. 26, 2298. https://doi.org/10.3201/eid2609.201749

Nicas, M., Nazaroff, W.W., Hubbard, A. (2005). Toward understanding the risk of secondary airborne infection: Emission of respirable pathogens. J. Occup. Environ. Hyg. 2, 143-154. https://doi.org/10.1080/15459620590918466

Owoade, O.K., Abiodun, P.O., Omokungbe, O.R., Fawole, O.G., Olise, F.S., Popoola, O.O.M., Jones, R.L., Hopke, P.K. (2021). Spatial-temporal variation and local source identification of air pollutants in a semi-urban settlement in Nigeria using low-cost sensors. Aerosol Air Qual. Res. 21, 200598. https://doi.org/10.4209/aaqr.200598

Papineni, R.S., Rosenthal, F.S. (1997). The size distribution of droplets in the exhaled breath of healthy human subjects. J. Aerosol Med. 10, 105-116. https://doi.org/10.1089/jam.1997.10.105

Rai, A.C., Kumar, P., Pilla, F., Skouloudis, A.N., Di Sabatino, S., Ratti, C., Yasar, A., Rickerby, D. (2017). End-user perspective of low-cost sensors for outdoor air pollution monitoring. Sci. Total Environ. 607-608, 691-705. https://doi.org/10.1016/j.scitotenv.2017.06.266

Shao, S., Zhou, D., He, R., Li, J., Zou, S., Mallery, K., Kumar, S., Yang, S., Hong, J. (2021). Risk 
assessment of airborne transmission of COVID-19 by asymptomatic individuals under different practical settings. J. Aerosol Sci. 151, 1-29. https://doi.org/10.1016/j.jaerosci.2020.105661

Traunmüller, H., Eriksson, A. (2000). Acoustic effects of variation in vocal effort by men, women, and children. J. Acoust. Soc. Am. 107, 3438-3451. https://doi.org/10.1121/1.429414

Wang, Y., Li, J., Jing, H., Zhang, Q., Jiang, J., Biswas, P. (2015). Laboratory evaluation and calibration of three low-cost particle sensors for particulate matter measurement. Aerosol Sci. Technol. 49, 1063-1077. https://doi.org/10.1080/02786826.2015.1100710

Yang, W., Marr, L.C. (2011). Dynamics of Airborne influenza A viruses indoors and dependence on humidity. PLoS ONE 6, e21481. https://doi.org/10.1371/journal.pone.0021481

Zayas, G., Chiang, M.C., Wong, E., MacDonald, F., Lange, C.F., Senthilselvan, A., King, M. (2012). Cough aerosol in healthy participants: Fundamental knowledge to optimize droplet-spread infectious respiratory disease management. BMC Pulm. Med. 12, 11. https://doi.org/10.1186/ 1471-2466-12-11 